somewhat greater detail than the former. These publications bring together the best data available approximately representative of latitude $40^{\circ}$ in central and eastern United States; they carry the values to altitudes that are much higher than aviation will ever need, and which will only be exceeded by the ordinates of the most extraordinary trajectories in artillery practice.

Turning again to the Survey, we find that the information is conveyed largely by charts and tables. The former present the matter as a whole, showing the vertical and geographical distribution of the several meteorological elements over the entire central and eastern United States. The latter are more precise, and are so conveniently arranged that the basic computational material for innumerable aerological studies may be found there awaiting the student. The text is brief, but clear and cogent, and calls attention to the significant features of the "survey."

The summary is based not only upon the kite stations of the Weather Bureau at present operating (Due West, S. C., excepted, since this station has been in operation only about a year and a half) but also upon the records of the Blue Hill Observatory and the Mount Weather Observatory. Thus data from eight aerological stations fairly well distributed, whose records vary from aboul two to seven years, have formed the basis of the survey.

The author shows that the values based upon a five-year record do not vary to any significant extent from those based upon a three-year record. As one might expect, the differences between the averages of the three and five-year record

... are greatest at or near the surface, where they amount in a few eases to $2^{\circ} \mathrm{C}$., in temperature, $1 \mathrm{mb}$. in barometric pressure and vapor pressure, and 10 per cent. in relative humidity. Differences in density are in no case significant. The seasonal means of all elements naturally show better agreement than the monthly means, and the annual means for the shorter and longer period are almost identical. It is thus evident that for the determination of normal values, particularly those for the months, a longer series of observations is necessary than that upon which the present suinmary is based.
Nevertheless, it is deemed satisfactory, for practical purposes, to regard the present means as normals. The author explains further that a longer record is necessary for the northern than for the southern stations, for the winter than for the summer (owing to the greater variability at the colder stations and in the colder season), and at lower than at higher altitudes above the surface. Thus, while 20 to 40 years are desirable lengths of record for surface data, a much shorter period is necessary for the upper levels.

To attempt to present in abstract the many striking and interesting features of the numerous diagrams would be impossible, owing to the concise presentation in the original. The large field of information is indicated by the following topics selected from the legends: Seasonal average temperatures, relative humidities, vapor pressures, for each station from the surface to about five kilometers; geographical distribution of mean summer and winter and annual lbarometric pressures, temperatures, relative humidity, vapor pressure, density and resultant winds; means seasonal wind velocities and the percentage frequency of different wind directions. All of these data extend from the surface to levels three to five kilometer's above sea-level.

The study of aerological data is two-fold, embracing average conditions and current data. This publication from the Aerological Division of the Weather Bureau forms an admirable contribution to the former field. Such contributions form a setting for the study of eurrent data. But, in spite of the resounding challenge of the upper air to the forecaster, the adequate and complete application of current aerological data must await the extension and amplification of the aerological réseau.

WASHINGTON, D. C.

$$
\text { C. LeRoy Meisinger }
$$

\section{SPECIAL ARTICLES DEFICIENCY OF ATMOSPHERIC DUST IN COAL}

IN connection with studies in eolian sedimentation the writer recently has become interested in an apparent discrepancy among (1) the rate of deposition of atmospherie dust, (2) 
the amount of ash in coal and (3) the rate of accumulation of vegetation leading to the formation of coal. To the casual observer it appears that there is not enough mineral matter in average coal to allow for the amount of atmospheric dust which would be deposited with the vegetation in the time ordinarily assumed to be required for the aceumulation of vegetable matter in coal.

From everyday observation the universal presence of atmospheric dust is apparent. The work of Free, ${ }^{1}$ Huntington, ${ }^{2}$ Reid $^{3}$ and others emphasizes the quantity as being much greater than commonly supposed. However, it is not the amount of dust in the air, but the amount that is caught in standing water or by vegetation that is significant in the present connection.

An average of the analyses of ash content for representative coals of the United States given by M. R. Campbell ${ }^{4}$ shows the following:

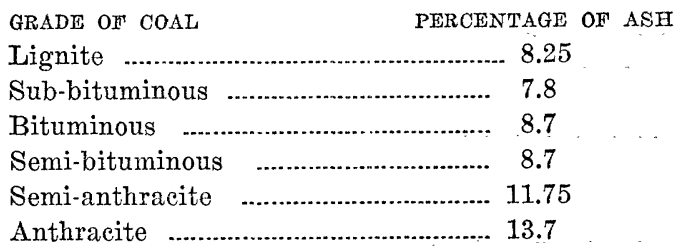

The last two averages are based only upon a few analyses.

It has been stated in text-books that about 9,000 years is required for the accumulation of sufficient vegetable matter to make one foot of bituminous coal. There is no reason to believe that this estimate is not at least approximately correct.

If dust was deposited from air during the coal-making periods at a rate of $1 / 1000$ inch per year-which at the present does not seem excessive-9 inches of dust would be accumulated during the period of 9,000 years. Conse-

1 Free, E. E.: “Movement of Soil Material by the Wind,' U. S. Dept. of Agriculture, Bull. 68.

2 Huntington, E.: "The Pulse of Asia."

3 Reid, Clement: "Dust and Soils," Geol. Mag., N. S., December, III, Vol. I, 1884, p. 165.

4 Campbell, M. R.: "The Coal Fields of the United States." General Introduction, $U$. S. Geol. Survey, Professional Paper 100-A. quently, with every foot of bituminous coal there should be 9 inches of atmospheric dust; that is, every foot of average coal would be about 75 per cent. dust. Even $1 / 10000$ inch of dust a year would result in coal with $71 / 2$ per cent. dust. And this does not take into account the vegetable mineral matter!

Apparently the problem leads to three questions: (1) Is the importance of dust grossly exaggerated? (2) Has the time so commonly assigned to the accumulation of a foot of coal been overestimated? (3) Were the areas which would serve as sources for dust during the coal-forming periods-and especially the Pennsylvanian-exceedingly restricted? The articles cited above emphasize the presence of dust in a way to induce the reader to believe that the importance of atmospheric dust has been overlooked rather than overestimated. If the time allotted for coal formation is fairly accurate, we would be led to believe that the sources and perhaps the means of transportation of dust were very much restricted and that the current evidence for a fairly moist, uniform climate on a land surface heavily covered by vegetation and restricted in area, becomes better established.

WaLdo S. GLOCK

The State University of Iowa

\section{THE AMERICAN CHEMICAL} SOCIETY

(Continued)

Division of ORganic Chemistry

H. T. Clarke, chairman

Frank C. Whitmore, secretary

The selective activation of alumina for decarboxylation or dehydration: HoMer ADKINs. In seeking experimental verification of the idea that the activity of a catalyst for an organic reaction in a heterogeneous system is conditioned by the magnitude of the distance between the atomic nuclei of the solid catalyst, five distinct kinds of alumina have been prepared from the aluminum alkoxides, aluminum hydroxide and hydrated alumina. It has been shown that the size and shape of the alkoxyl group is a determining factor in the relative extent to which decarboxylation or dehydration is induced in esters, alcohols and acids by the alumina prepared from the solid alkoxides. An increase in "molecular porosity," 